\title{
1 One of the gang: social group dynamics in a juvenile passerine
}

\section{2 bird}

Victoria R. Franks ${ }^{1,2}$, John G. Ewen², Mhairi McCready², J. Marcus Rowcliffe ${ }^{2}$, Donal Smith ${ }^{2,3}$, Rose Thorogood ${ }^{1,4,5}$

${ }^{1}$ Department of Zoology, University of Cambridge, Downing Street, Cambridge, CB2 3EJ, U.K.;

2 Institute of Zoology, Zoological Society of London, Regent's Park, London, NW1 4RY, U.K.;

${ }^{3}$ School of Environment \& Life Sciences, University of Salford, Salford, M5 4WT, U.K.;

${ }^{4}$ Helsinki Institute of Life Science (HiLIFE), University of Helsinki, Finland;

${ }^{5}$ Research program in Organismal and Evolutionary Biology, Faculty of Biological and Environmental Sciences, University of Helsinki, Finland.

*Corresponding author email: vix_franks@live.com

\section{Abstract}

Living in groups comes with many potential benefits, especially for juveniles. Naïve individuals may learn how to forage, or avoid predators through group vigilance. Understanding these benefits, however, requires an appreciation of the opportunities juveniles have to associate with (and learn from) others. Here we describe social groups in terms of residency, movement, relatedness, and social associations from the perspective of juvenile hihi, a threatened New Zealand passerine bird. Over three years, we identified individuals in groups, their relatedness, and behavioural interactions. Using multistate analysis, we compared movement and residency of adults and juveniles and found that groups were composed predominately of juveniles which remained at group sites for longer than more transient adults. Movement of juveniles between groups did occur but was generally low. There was no evidence that siblings and parents were likely to be seen in groups together. With an initial understanding of group structure, we next asked what characteristics predicted assortment in social network associations. By identifying groups of co-occurring juveniles from time-stamped observations of individual hihi and building a social network, we found that juveniles were most likely to associate with other juveniles. Associations were also predominantly based on locations where hihi spent the most time, reflecting limited movement among separate groups. We suggest groups are best described as "gangs" where young hihi have little interaction with adults. These spatially-separated groups of juveniles may have consequences for social information use during the first few months of independence in young birds. 


\section{Introduction}

Social groups are found across the animal kingdom (Ward and Webster, 2016). Generally, group living is thought to provide advantages such as better foraging opportunities if groups can collectively outcompete other more dominant animals, and protection from predators through shared vigilance (Rubenstein, 1978; Molvar and Bowyer, 1994; Gompper, 1996; Hass and Valenzuela, 2002; Le Bohec, Gauthier-Clerc and Le Maho, 2005). Sociality may benefit juveniles in particular, as they are inexperienced compared to adults (Galef and Laland, 2005) and can be less adept at finding food (Sullivan, 1989; Lind and Welsh, 1994; Franks and Thorogood, 2018) or avoiding predators by themselves (Naef-Daenzer, Widmer and Nuber, 2001). Therefore, juveniles may be able to use information from others in groups ("social information") to reduce their uncertainty about how best to behave (Dall et al., 2005). However, who juveniles encounter in groups will affect the opportunities they have to learn socially (Seppänen et al., 2007; Krause et al., 2015), along with additionally impacting on other consequences of group living such as risk of contracting disease (Godfrey et al., 2009; Drewe, 2010). Therefore, the dynamics of groups (where groups form, when they form, and which individuals group) need to be quantified to understand why animals are social, especially juveniles (Krause and Ruxton, 2002; Ward and Webster, 2016).

In young wild birds, there are examples of three types of groups which vary in age structure, relatedness structure, and site stability. Firstly, birds are well-known to form mobile foraging units or "flocks", with no particular structure by relatedness or age (so are not unique to juveniles) (Morse, 1978; Saitou, 1978, 1979; Ekman, 1989; Templeton et al., 2012). All group members can access ephemeral food sources as the group moves across an environment, and they also share costs of predator vigilance (Rubenstein, 1978; Molvar and Bowyer, 1994; Hass and Valenzuela, 2002; Sutton, Hoskins and Arnould, 2015). Secondly, juveniles can form groups without adults, such as "gangs" in ravens (Corvus corax) (Dall and Wright, 2009). Gangs are similar to flocks in that their main function is to access ephemeral food resources; however, gangs operate around stable roosting sites which act as information centres (Dall and Wright, 2009) and also allow juveniles to out-compete more dominant adults (Wright, Stone and 
congregations as "crèches". These groups contrast with gangs or flocks because crèches form before juveniles become fully independent from parents, and serve to promote juvenile survival as parents actively care for their young with food provisioning and vigilance (Balda and Balda, 1978; Marzluff and Balda, 1992; Clayton and Emery, 2007). Despite group structure being a crucial part of the social environment of juveniles, little is known outside of these examples. Overall, juvenile behaviour is understudied in general, especially in birds (Templeton et al., 2012).

One way groups may help juveniles overcome their naivety is by providing opportunities to learn rapidly when interacting with group members (Coussi-Korbel and Fragaszy, 1995; Krause and Ruxton, 2002). If groups are comprised of different age classes, or individuals that use the environment in different ways, juveniles may encounter a range of potential social information (Seppänen et al., 2007; PinterWollman et al., 2013). For example, juveniles in flocks encounter both experienced adults and other juveniles, so information about ephemeral food sources can be shared among group members ("oblique" and "horizontal" transmission, respectively (van Schaik, 2010)). In gangs where associations are largely between juveniles only, interactions can include "social play" (documented in species such as ravens (Heinrich and Smolker, 1998)), where at least two individuals engage in a reciprocated behaviour and alternate between roles, and potentially share information (Diamond and Bond, 2003). However, the presence of many naïve individuals in gangs could increase the risk of associating with misinformed peers, especially if some individuals are more social than others (Pruitt et al., 2016). Across the animal kingdom, genetically-related groups such as crèches promote associations between parents and offspring (Balda and Balda, 1978; Clayton and Emery, 2007) that allow for learning (e.g. European shags Phalacrocorax aristotelis: Velando, 2001; ravens Corvus corax: Schwab et al., 2008; vervet monkeys Chlorocebus pygerythrus: van de Waal, Bshary and Whiten, 2014) and can even facilitate teaching (e.g. meerkats Suricata suricatta (Thornton, 2006; Thornton and Raihani, 2010)). Alternately, some studies suggest associations with non-kin can still be beneficial as these individuals may have a different range of experiences (Hatch and Lefebvre, 1997). Describing group structures and understanding how these affect associations should therefore help us to understand the benefits of group living for juveniles more clearly (Sih, Hanser and McHugh, 2009). 
Analysing group behaviour in space and time can quantify broad-scale consistencies to show who groups, when and where. However, it does not fully capture how individuals interact as a consequence of group structure. Social network analysis can overcome this problem (Wey et al., 2008); animals form social networks through non-random preferred and avoided associations which can be quantified and analysed statistically (Krause and Ruxton, 2002; Krause, Lusseau and James, 2009; Sih, Hanser and McHugh, 2009; Krause et al., 2015). Therefore, here we first used a form of re-sighting analysis to consider movement, residency and relatedness in groups of juvenile and adult birds. We then compiled social networks to investigate how movement, residency and relatedness affected associations between individuals. Finally, we observed interactions between grouping individuals to understand how social behaviour may influence information sharing. Our study species was the hihi (Notiomystis cincta), an endemic New Zealand passerine. Hihi provide a good example where juveniles are known anecdotally to form groups during early life, although these have not been studied systematically before. We aimed, therefore, to describe group formation and membership, compare them to juvenile groups in other species, and understand how group characteristics affected associations (Table 1). If hihi groups were crèches, we predicted both adults (parents) and juveniles (siblings) to be consistently sighted together in groups. However, we would expect different structure if groups were gangs (juveniles should be present much more than adults) or flocks (individuals would not remain in one site; adults and juveniles would be present but unrelated). 
Table 1. Predictions for group structure and social associations for juvenile hihi, with reference to previously-described groups of birds. All group types can be compared to a "null" unstructured group of randomly-associating individuals.

\begin{tabular}{|c|c|c|c|c|}
\hline \multirow[b]{2}{*}{ Group characteristics } & \multicolumn{4}{|c|}{ Group type } \\
\hline & $\begin{array}{l}\text { Flock } \\
\text { (Saitou } \\
1978 ; \\
1979)\end{array}$ & $\begin{array}{l}\text { Gang } \\
\text { (Marzluff } \\
\text { et al., } \\
\text { 1996) }\end{array}$ & $\begin{array}{l}\text { Crèche } \\
\text { (Marzluff } \\
\text { \& Balda } \\
\text { 1992) }\end{array}$ & Null \\
\hline $\begin{array}{l}\text { (1) Age composition: } \\
\text { Juveniles are more resident in groups than adults } \\
\text { - Juveniles re-sighted more days than adults; } \\
\text { - Age structures associations } \\
\text { - Juveniles interact }\end{array}$ & No & Yes & No & No \\
\hline $\begin{array}{l}\text { (2) Spatial structure: } \\
\text { Juveniles group in consistent locations } \\
\text { - Low movement between separate groups; } \\
\text { - Location structures associations }\end{array}$ & No & Yes & Yes & No \\
\hline $\begin{array}{l}\text { (3) Relatedness: } \\
\text { Groups contain parents and offspring } \\
\text { - Juveniles consistently sighted with } \\
\text { parents/siblings; } \\
\text { - } \quad \text { Relatedness structures associations } \\
\end{array}$ & No & No & Yes & No \\
\hline (4) Groups random (across/within years) & No & No & No & Yes \\
\hline
\end{tabular}

125

Methods

STUDY POPULATION

130 Our study was conducted over three years $(2015$ - 2017) on Tiritiri Matangi Island (Auckland, New

131 Zealand, $36^{\circ} 36^{\prime} 00.7^{\prime \prime S} 174^{\circ} 53^{\prime} 21.7^{\prime \prime E}$ ), between January - April when juvenile hihi (birds in their first

132 year) had fledged and dispersed from nests. This $2.5 \mathrm{~km}^{2}$ island is characterised by a central longitudinal

133 ridge (60-80m altitude) with a series of latitudinal ridges and gullies on either side covered in a mixture

134 of original and replanted native bush. Supplementary sugar water feeders are provided year-round for

135 hihi at five sites across the island. This is a closed population with no immigration or emigration (except

136 through birth and mortality) and all individuals are uniquely identifiable from coloured leg ring

137 combinations. The population varied between 180 and 270 individuals over the three years, with similar

138 proportions of juveniles and adults (second year or older) each year (Smith and Ewen, 2015; McCready 
and Ewen, 2016, 2017). Every year, all breeding attempts are monitored and identities of breeding pairs recorded. During this study, parentage and siblings were assigned based on social relationships.

141 Although there is variable extra-pair paternity in hihi (Ewen, Armstrong and Lambert, 1999; Brekke et al., 2013), all nest-mates were most likely to be at least maternal-siblings (there is no evidence of

143 conspecific brood parasitism in hihi) and the social male cares for the offspring in his nest (Ewen and

144 Armstrong, 2000). The first year of our study (2015) was a poorer breeding season than 2016 and 2017

145 (2015: 89 fledglings; 2016: 132 fledglings; 2017: 151 fledglings); thus, we accounted for year in any 146 analyses using combined data.

\section{DETECTING GROUPS}

150 Each year, we surveyed for groups between January - February in spatially-separated areas of forest 151 habitat. In 2016 and 2017, we increased the search area to ensure no other potential groups were 152 missed. The numbers of unique juveniles were recorded for one hour in each location, and group sites 153 were assigned after two weeks if we saw at least three juveniles during more than $80 \%$ of 10 surveys 154 per location. We further confirmed that there were no other sites with higher numbers of juveniles during 155 the annual February census of the population, which is conducted every year by trained conservation 156 staff who survey the entire island over 40 hours. We then continued to survey group locations from 157 February - April, using one-hour surveys divided into 30-second time blocks (one survey = 120 blocks). 158 Within each block we recorded the identity of all hihi (both juvenile and adult) perched within a 10-metre 159 radius of the observer. We recorded individuals present across blocks to determine presence to the 160 nearest 30 seconds, and also the occurrence of behavioural interactions and the identities of the 161 individuals involved (Table 2; Figure 1). Interactions were classed as "directed" if there were clear

162 initiators; however, for some behaviours individuals were only ever seen to interact equally, so we 163 classified these as "undirected" (Table 2). All observations were made with binoculars (Zeiss Conquest ${ }^{\circledR}$ $164 \mathrm{HD} 8 \times 42$ ) by one observer (VF). In total we recorded 15 hours per group site in 2015, and 25 hours per 165 site in 2016 and 2017; surveys were distributed evenly across the three months. 
Table 2. Ethogram of common interactions observed between juveniles in groups, and their definitions.

170

\begin{tabular}{|c|c|c|c|}
\hline & & Interaction & Description \\
\hline $\begin{array}{l}\bar{D} \\
\stackrel{d}{0} \\
\Phi \\
. \overline{0}\end{array}$ & $\begin{array}{l}0 \\
\stackrel{0}{7} \\
\stackrel{0}{2} \\
\frac{\pi}{0} \\
0\end{array}$ & Chased & $\begin{array}{l}\text { Individual moves towards another perched hihi, displaces it, and then } \\
\text { continues moving in the same direction as the second bird. } \\
\text { Individual moves away from its original perch after another hihi has } \\
\text { initiated moving towards the focal individual } \\
\text { Individual leaves a perch to move in same direction as another hihi } \\
\text { that moves off before focal individual. } \\
\text { Individual leaves a perch before another perched bird, and the second } \\
\text { bird moves off in the same direction as the focal individual. }\end{array}$ \\
\hline & 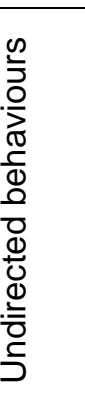 & Huddle & $\begin{array}{l}\text { Two or more birds perch touching side-by-side and do not move from } \\
\text { position on perch. May include allopreening. } \\
\text { Two or more birds perch touching side-by-side, then peck at each } \\
\text { other, hang up-side down on branch, shuffle next to each other along } \\
\text { branch. }\end{array}$ \\
\hline
\end{tabular}

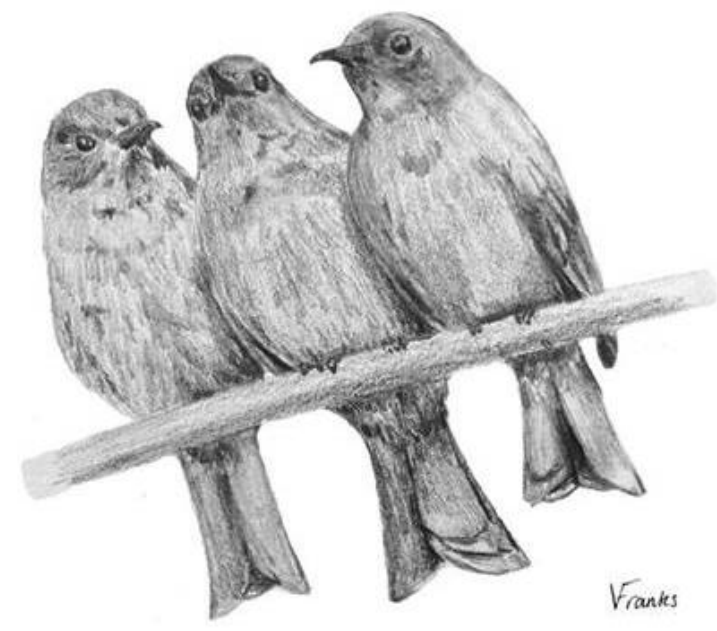

Figure 1. Sketch of huddle behaviour, with three juvenile hihi perching sideby-side on a branch. 


\section{DATA ANALYSIS}

178

\section{Re-sighting and movement analysis}

180

181 We first used a multistate approach in Program MARK (version 9.0) (White and Burnham, 1999) to understand residency in group sites and movement between sites for juveniles and adults. Multistate analyses estimate survival $(S)$ and re-sighting $(\rho)$ of identifiable individuals of different "states" from repeated sightings across replicated surveys, along with likelihood of movement between states $(\psi)$ (White, Kendall and Barker, 2006). Survival and re-sighting are often inherently linked and considered together to investigate population dynamics (i.e. to identify true mortality instead of absence of detection). However, in our study we used these three parameters in a novel way to determine different patterns of hihi group structure. We assumed mortality was constant over our short study periods each year (Jolly, 1982), supported by previous studies of adult and juvenile survival in this population (Low and Pärt, 2009). Including varying survival by age in preliminary exploratory models also indicated low mortality (98-99\% survival each year for both ages across all observational surveys; results not presented) suggesting birds were alive throughout the study period. We could then use $\rho$ to quantify presence/absence in groups (larger values of $\rho$ indicated high residence within groups as opposed to independent living), and track movement between groups using state transitions (higher values of $\psi$ indicating greater movement between known groups). In 2016 we verified that our survey method was reliable (see Appendix) to be confident in estimating $\rho$.

198 We constructed re-sighting histories for each bird seen each year to represent if, and in which group, it was seen. Different groups were not surveyed at the same time (due to one observer), so we combined surveys together to create occasions that represented every group site. There was a maximum of two 201 days between combined surveys to limit movement between groups within a survey occasion; if this did occur we took the newest site as the site of residence for that individual in that occasion to account for movement (this occurred rarely: $2015=1 / 656$ re-sightings; $2016=9 / 1974$ re-sightings; $2017=7 / 3180$ re-sightings). Thus, there were 8 survey occasions in 2015, 14 in 2016, and 20 in 2017. An example resighting history for one individual in 2015 is "aa0abbbb", where the bird was seen in group "a" in survey 
group "b" for the remainder of survey occasions. We also specified if an individual was juvenile or adult with its re-sighting history. Therefore, our general starting model using our encounter histories in all 209 three years was:

\section{$S(.) \rho\left(\right.$ age $e^{\star}$ survey occasion $) \psi($ age + group $)$}

211 Here, we quantified different residency in groups between adults and juveniles by assessing if resighting $\rho$ varied across each survey occasion and between age groups, and if movement $\psi$ between 213 groups also varied with age. For $\psi$, we specified group differences as varying distance and topology between groups could affect likelihood of moving between each group (Martin et al., 2006; Strandburg-

215 Peshkin et al., 2017). Finally, different intervals between survey occasions were accounted for so likelihoods were not confounded by time.

218 Assessing fit allows for accurate inference from more reduced models (Burnham and Anderson, 2002;

219 Cam et al., 2004; Martin et al., 2006). Therefore we assessed goodness-of-fit (GOF) of our starting models each year using median $\hat{c}$ (variance inflation factor, a measure of overdispersion), which is

221 generated by assessing the distribution of model deviances (White and Burnham, 1999; Gath, 2017).

222 Values of median $\hat{c}>1$ suggest overdispersion that needs to be corrected for in analyses while values $223>4$ suggest a structural failure of the general model (Burnham and Anderson, 2002). Each year, there 224 were low levels of overdispersion (median ĉ: $2015=1.51 ; 2016=1.39 ; 2017=1.72$ ) so we used the 225 value of median $\hat{c}$ as a correction factor for all further multistate analyses.

227 For each year, we constructed sets of models with all possible combinations of $\rho$ and $\psi$ parameters and 228 ranked these by their corrected Quasi-Akaike Information Criterion (QAICc) values. AICc values 229 represent the change in fit in comparison to the top-ranked model, and QAICc is used when $\hat{c}$ is 230 corrected following GOF testing. Any model <2 QAICc units from the top-ranked model were considered 231 equally well-supported. We also calculated QAICc weights for each model based on change in QAICc 232 value from top-ranked model, which gave the relative likelihood that it was the most appropriate model 233 (Burnham and Anderson, 2002). Any parameters included in models with QAICc weight $>0.00$ were 234 included in model-averaging to calculate effect sizes and 95\% confidence intervals. Any parameter with 235 a confidence interval that did not include 0.00 was considered to have a significant effect. 
237 All further analyses were conducted in R (version 3.5.0) (R Core Team, 2017). To determine if juveniles

238 were using the same group sites as their parents and maternal-siblings, using each juvenile's re-sighting 239 history we calculated, per bird, the proportion of occasions it was seen in the same group as either of 240 its parents, and the proportion of occasions it was seen in the same group as its maternal-siblings. We 241 excluded any juveniles seen in one survey only as we could not calculate a proportion for these (N: 2015 $242=10 ; 2016=18 ; 2017=10)$. When calculating proportions of time spent with maternal-siblings we also 243 excluded any juveniles from single-fledgling nests or those with no maternal-siblings seen during our 244 surveys (which may have died after fledging) ( $N$ : $2015=7 ; 2016=10 ; 2017=8$ ). We assessed if 245 juveniles that grouped closer to their nest-of-origin were more likely to co-occur with their maternal246 siblings. We used a binomial Generalised Linear Model (GLM) where proportion of surveys with 247 maternal-siblings was the response variable; using a proportion meant we could analyse all years 248 together. Our predictors were proximity to nest-of-origin (distance to nearest $50 \mathrm{~m}$ from group site to 249 nest-of-origin, measured using Google Maps), number of surveys to ensure co-occurrence with 250 maternal-siblings was not due to sampling bias, and year of survey $(2015,2016,2017)$ to compare 251 patterns among years. We constructed a set of candidate models including all combinations of predictors 252 and ranked models by their AICc values. For any model <2 AICc units larger than the top-ranked model, 253 we calculated averaged effect sizes ( $\pm 95 \%$ confidence intervals) for predictors using the package 254 AlCcmodavg (version 2.1-1) (Mazerolle, 2017). Based on the evidence from this initial exploration (see 255 Results) we did not analyse effects of relatedness further using MARK, or in social network analysis.

\section{Social network analysis}

259 We constructed a social network for each year separately using the R package asnipe (version 1.1.9) 260 (Farine, 2013). First we used the "gmmevents" function to detect temporal clusters in our time-stamped 261 (to within 30s) sightings data and build an association matrix (Farine, 2013; Psorakis et al., 2015). Using 262 this approach avoids artificially restricted associations, which can occur using a more fixed time-window 263 approach (Psorakis et al., 2015). To validate if "gmmevents" groups represented true associations, we 264 then compared the length of time (number of sequential observation blocks) we re-sighted hihi during 265 observations to event lengths generated by "gmmevents". All networks were weighted, which 
incorporates both the number and strength of social connections and are considered more robust than binary networks (Farine, 2014). Any hihi with fewer than 3 observation records were not included in networks (juvenile $N: 2015=6 ; 2016=1 ; 2017=4$; adult $N: 2015=12 ; 2016=82017=7$ ).

As network data is not independent and thus violates the assumptions of many statistical tests, we compared observed networks to randomised networks as a null model to test hypotheses (Croft et al., 2011; Farine and Whitehead, 2015; Farine, 2017). All randomised networks were generated using permutations of the data-stream in asnipe, which randomly swaps records of individuals and is considered best practice instead of node-based permutations because it maintains original data structure and controls for sampling bias (Farine, 2013, 2014, 2017; Farine and Whitehead, 2015). Significance was calculated by dividing the number of times the test statistic of the real network was smaller than the test statistics of randomised networks by 1000 (the number of permutations). All $P$ values generated using random networks comparisons are specified here as $P_{\text {rand. }}$ Visualisations of networks were constructed in Gephi (version 0.9.2) (Bastian, Heymann and Jacomy, 2009) with a forceatlas layout that clustered together more strongly associating nodes.

We tested if hihi formed non-random associations in their groups compared to permuted networks using the coefficient of variation ("cv"). The value of cv describes variation in edge weights across a network: extreme values of $\mathrm{cv}$ are 0 and 10 , but any values over 0.6 are considered to represent differentiated networks (groups are comprised of strong, repeated connections) (Farine and Whitehead 2015). We then explored if non-random associations were explained by strengths of bonds between individuals depending on their age class (adult and juvenile "assortment"). We tested for assortment in edge weights using the assortnet package (version 0.12) (Farine, 2014) to generate an assortment coefficient $(r$, a value from -1 to 1 ) which we compared to the $r$ values of permuted networks. Positive assortment

290 suggests similarly characterised individuals form stronger associations, while negative assortment 291 indicates disassociation (Newman, 2002; Farine, 2014). Following evidence of different levels of 292 associations between the different age groups, we considered if site use patterns uncovered during 293 multistate analysis explained associations between juveniles. In a juvenile-only network we confirmed 294 non-random associations across groups, because of evidence for differential site usage by individuals 295 from our initial multistate analysis which could have structured associations across sites (Farine, 2017). 
We also investigated associations within groups to assess if juveniles had non-random associations on a finer scale. We compared the $\mathrm{cr}$ values of our network to $\mathrm{cr}$ values from permuted networks with data swapped across groups and then within groups. Finally, we explored assortment in association strengths depending on the primary group each juvenile was most commonly recorded in across all surveys, by comparing to the assortment coefficients of permuted networks.

\section{1}

\section{Behavioural interactions}

303

304 To explore how adult and juvenile hihi behaved in groups, for each individual we calculated the proportion of its observations where it was recorded interacting with another bird (separate observations were more than thirty seconds apart) and compared proportions between ages with a Wilcoxon rank sum test. Using proportions accounted for differences in survey effort so that we could combine data from all years. For each juvenile, we then calculated the proportion of total interactions allocated to each behaviour in Table 3.2 and explored if particular types of interactions were correlated using a Principle Components Analysis (PCA) (Budaev, 2010). For any principle components that explained $75 \%$ of variance, we next assessed how they correlated with network associations and whether juveniles that behaved in particular ways were more central in the network. We extracted weighted degree scores

313 from our network for each juvenile each year, which explained the number and strength of associations

314 for each bird and thus its placement in the network (animals with more connections tend to be placed more centrally (Krause et al., 2015)). We ranked degrees and divided ranks by the number of juveniles each year, to calculate a proportion rank that was comparable across the different years of the study.

317 We then constructed a GLM with each juvenile's degree rank as the response and any identified 318 principle components as predictors. To account for non-independence in network data, we generated

$319 P$-values by comparing our observed coefficient to coefficients generated from 1000 models where 320 degree rank values were calculated from permuted networks (Farine and Whitehead, 2015). 


\section{Results}

There were two groups in 2015 and three groups for each of 2016 and 2017, in gully areas (away from feeders) containing water sources and mixed forest. Each year, hihi had multiple associates (mean \pm S.E. number of associates: juveniles: $2015=15.71 \pm 1.59 ; 2016=24.01 \pm 1.63 ; 2017=25.29 \pm 1.84$; adults: $2015=8.21 \pm 1.00 ; 2016=8.57 \pm 1.23 ; 2017=9.84 \pm 1.00)$. The 2015 network represented 379 associations between 33 adults and 31 juveniles; 2016, 1168 associations between 54 adults and 78 juveniles; and 2017, 1400 associations between 61 adults and 87 juveniles. The "gmmevents" event lengths defining associations corresponded to the length of time hihi were re-sighted across consecutive time blocks (median length of event windows (seconds): $2015=119.79,2016=90.44,2017=90.75$; median re-sighting periods (seconds): $2015=90,2016=90,2017=120$; Wilcoxon rank sum test comparing length of event windows to re-sighting periods, 2015: $W=123240, P=0.06,2016: W=$ 541210, $P=0.54 ; 2017: W=824380, P=0.17)$. Both the juvenile/adult and juvenile-only networks showed non-random (preferred and avoided) associations each year (juvenile/adult network: 2015: cv

$339=2.64, P_{\text {rand }}=0.03 ; 2016: \mathrm{cv}=3.60, P_{\text {rand }}<0.001 ; 2017: \mathrm{cv}=3.56, P_{\text {rand }}=0.008$; juvenile-only network: $2015: \mathrm{cv}=1.77 ; 2016: \mathrm{cv}=2.31 ; 2017: \mathrm{cv}=2.46$; in all years, $P_{\text {rand }}$ values across-location and withinlocation < 0.001).

\section{WERE JUVENILES MORE RESIDENT IN GROUPS THAN ADULTS?}

There was no difference in the numbers of adults and juveniles detected within and across years

346 (Fisher's exact test: $N$ juveniles $=207 ; N$ adults $=175 ; P=0.18$ ). However, juveniles were present on 347 more days than adults (Wilcoxon rank sum test comparing number of days adults and juveniles were 348 re-sighted: 2015: $W=235.5, P<0.001 ; 2015: W=235.5, P<0.001 ; 2015: W=235.5, P<0.001)$.

349 Consequently, our multistate analysis estimated that juveniles were re-sighted at least twice as 350 frequently in successive survey occasions compared to adults in all three years (top-ranked models 351 explaining re-sighting included age; Table 3; Figure 2a, b, c; Supplementary Table 1; juveniles N: 2015 $352=37 ; 2016=79 ; 2017=91$; adults $N: 2015=45 ; 2016=62 ; 2017=68)$. Re-sighting was constant in 3532015 and 2017 but varied across survey occasions in 2016 for both adults and juveniles (Supplementary 354 Table 1) suggesting there were small variations in social behavior across years. 
356 Networks reflected these general patterns in residency and showed strong positive assortment by age:

357 each year at least $38 \%$ of associations occurred between juveniles only (Table $4 ; 2015: r=0.15, P_{\text {rand }}$ $\left.358<0.001 ; 2016: r=0.25, P_{\text {rand }}=0.028 ; 2017: r=0.19, P_{\text {rand }}=0.001\right)$. Juveniles were also more likely to 359 interact with others compared to adult hihi (Wilcoxon rank sum test: $W=8554.5, P<0.001$; although 360 67/207 juveniles were never observed interacting). Principle Component 1 (PC1) was strongly 361 negatively loaded to "playfight" (Table 5; Supplementary Figure 1), which was the most frequent 362 interaction (mean \pm S.E. proportion of total interactions per juvenile that were playfights $=0.25 \pm 0.02$ ). 363 Most remaining variation was represented by PC2 and PC3 (Table 5; Supplementary Figure 1). PC2 364 was loaded most strongly by "huddle" and "chased", but in opposite directions; this quantified variation 365 in potential affiliative behaviours, because positive scores indicated individuals that huddled more were 366 chased less often. PC3, on the other hand, was loaded negatively by "huddle" and "chased", but 367 positively by "chase". This third component described variation where individuals that huddled less 368 chased others more. For individuals that interacted, these three behavioural components did not 369 significantly predict variation in network position (Table 6). However, there was a non-significant 370 tendency that individuals with a more positive PC3 score (more likely to chase, less likely to be chased 371 or huddle) had higher degree ranks (Table 6) suggesting that more dominant individuals may have 372 tended towards being more social. 
Table 3. Model-averaged estimates of re-sighting $(\rho)$ and movement $(\Psi)$ for adult and juvenile hihi in (a) 2015; (b) 2016 and (c) 2017. Estimates generated from multistate models in Supplementary Table 1 which had $\triangle$ QAIC weight $>0.00$; significant estimates where confidence intervals $(\mathrm{LCl}, \mathrm{UCl})$ did not span 0.00 are highlighted in bold. Letters for movement correspond to group sites in Figure $2 \mathrm{~d}$, e, f.

(a)

\begin{tabular}{llll}
\hline & Est. & LCI & UCI \\
\hline$\rho$ Adult & $\mathbf{0 . 2 3}$ & $\mathbf{0 . 1 2}$ & $\mathbf{0 . 4 1}$ \\
$\rho$ Juvenile & $\mathbf{0 . 5 9}$ & $\mathbf{0 . 4 2}$ & $\mathbf{0 . 7 3}$ \\
$\boldsymbol{\Psi}$ a to b Adult & 0.01 & 0.00 & 0.02 \\
$\boldsymbol{\Psi}$ a to b Juvenile & $\mathbf{0 . 0 9}$ & $\mathbf{0 . 0 1}$ & $\mathbf{0 . 4 7}$ \\
$\boldsymbol{\psi}$ b to a Adult & 0.00 & -0.01 & 0.02 \\
$\boldsymbol{\Psi}$ b to a Juvenile & 0.02 & 0.00 & 0.15 \\
\hline
\end{tabular}

(b)

\begin{tabular}{lccc} 
& Est. & LCI & UCI \\
\hline $\boldsymbol{\rho}$ Adult & $\mathbf{0 . 1 7}$ & $\mathbf{0 . 0 9}$ & $\mathbf{0 . 3 1}$ \\
$\boldsymbol{\rho}$ Juvenile & $\mathbf{0 . 3 6}$ & $\mathbf{0 . 2 2}$ & $\mathbf{0 . 5 3}$ \\
$\boldsymbol{\psi}$ b to c Adult & 0.00 & 0.00 & 0.00 \\
$\boldsymbol{\Psi}$ b to c Juvenile & 0.00 & -0.02 & 0.02 \\
$\boldsymbol{\Psi}$ b to d Adult & $\mathbf{0 . 0 4}$ & $\mathbf{0 . 0 1}$ & $\mathbf{0 . 2 3}$ \\
$\boldsymbol{\Psi}$ b to d Juvenile & $\mathbf{0 . 1 5}$ & $\mathbf{0 . 0 9}$ & $\mathbf{0 . 3 1}$ \\
$\boldsymbol{\Psi}$ c to b Adult & 0.00 & -0.01 & 0.02 \\
$\boldsymbol{\Psi}$ c to b Juvenile & 0.02 & 0.00 & 0.11 \\
$\boldsymbol{\Psi}$ c to d Adult & 0.02 & 0.00 & 0.11 \\
$\boldsymbol{\Psi}$ c to d Juvenile & $\mathbf{0 . 0 9}$ & $\mathbf{0 . 0 4}$ & $\mathbf{0 . 1 9}$ \\
$\boldsymbol{\Psi}$ d to c Adult & 0.01 & 0.00 & 0.07 \\
$\boldsymbol{\Psi}$ d to c Juvenile & $\mathbf{0 . 0 4}$ & $\mathbf{0 . 0 2}$ & $\mathbf{0 . 1 0}$ \\
$\boldsymbol{\Psi}$ d to b Adult & 0.01 & -0.01 & 0.03 \\
$\boldsymbol{\Psi}$ d to b Juvenile & $\mathbf{0 . 0 4}$ & $\mathbf{0 . 0 1}$ & $\mathbf{0 . 2 3}$ \\
\hline
\end{tabular}

(c)

\begin{tabular}{llll}
\hline & Est. & LCl & UCI \\
\hline $\boldsymbol{\rho}$ Adult & $\mathbf{0 . 2 2}$ & $\mathbf{0 . 1 7}$ & $\mathbf{0 . 2 8}$ \\
$\boldsymbol{\rho}$ Juvenile & $\mathbf{0 . 4 4}$ & $\mathbf{0 . 4 0}$ & $\mathbf{0 . 4 9}$ \\
$\boldsymbol{\psi}$ b to d Adult & 0.01 & 0.00 & 0.02 \\
$\boldsymbol{\Psi}$ b to d Juvenile & $\mathbf{0 . 0 5}$ & $\mathbf{0 . 0 3}$ & $\mathbf{0 . 1 1}$ \\
$\boldsymbol{\psi}$ b to e Adult & 0.00 & 0.00 & 0.01 \\
$\boldsymbol{\psi}$ b to e Juvenile & 0.01 & 0.00 & 0.09 \\
$\boldsymbol{\psi}$ d to b Adult & 0.00 & 0.00 & 0.01 \\
$\boldsymbol{\Psi}$ d to b Juvenile & $\mathbf{0 . 0 2}$ & $\mathbf{0 . 0 1}$ & $\mathbf{0 . 0 4}$ \\
$\boldsymbol{\Psi}$ d to e Adult & 0.01 & 0.00 & 0.02 \\
$\boldsymbol{\Psi}$ d to e Juvenile & $\mathbf{0 . 0 4}$ & $\mathbf{0 . 0 2}$ & $\mathbf{0 . 0 8}$ \\
$\boldsymbol{\Psi}$ e to b Adult & 0.00 & 0.00 & 0.01 \\
$\boldsymbol{\Psi}$ e to b Juvenile & 0.01 & 0.00 & 0.02 \\
$\boldsymbol{\Psi}$ e to d Adult & $\mathbf{0 . 0 4}$ & $\mathbf{0 . 0 1}$ & $\mathbf{0 . 1 3}$ \\
$\boldsymbol{\Psi}$ e to d Juvenile & $\mathbf{0 . 2 0}$ & $\mathbf{0 . 1 1}$ & $\mathbf{0 . 3 3}$ \\
\hline
\end{tabular}



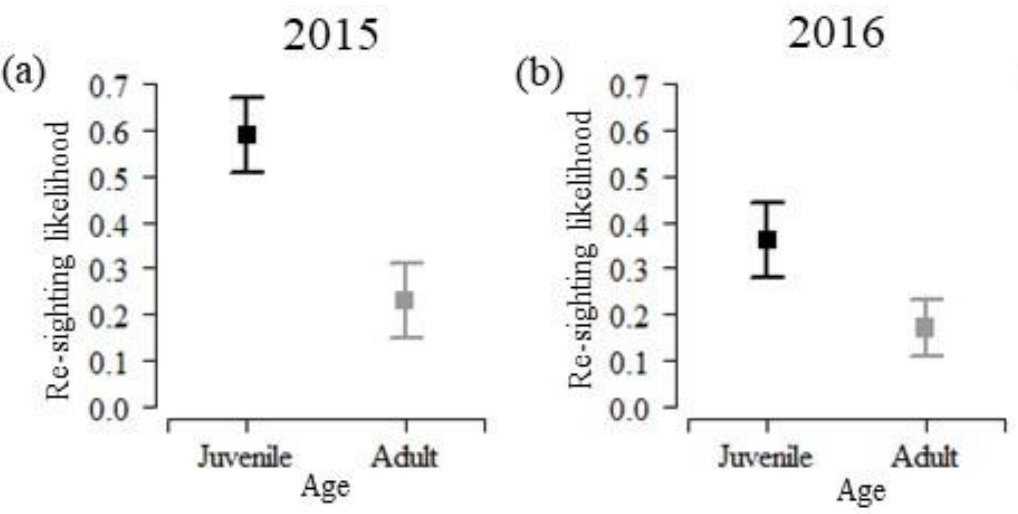

(d)

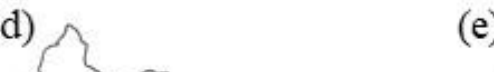

(g)

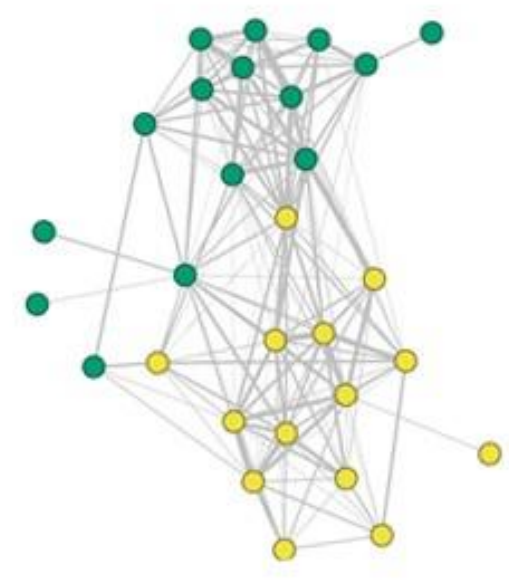

(h)

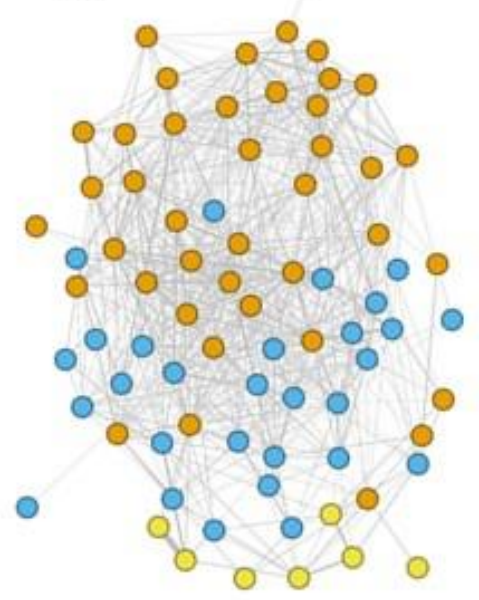

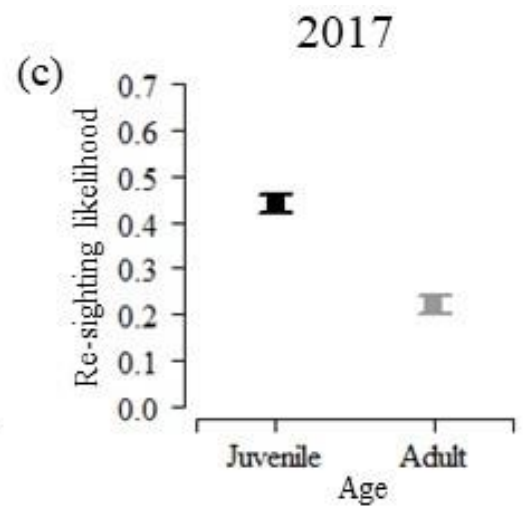

(f)

Figure 2. Re-sighting (a-c), movement (d-f) and associations ( $g-i)$ for groups (left = 2015; middle $=2016$; right $=2017$ ); $(\mathrm{a}-\mathrm{c})$ represent mean $( \pm$ S.E. ) re-sighting estimates for juveniles (black lines) and adults (grey lines); (d-f) show movements (dashed lines with arrowheads) between different groups for juveniles ("J") and adults ("A") (significant movements from Table 3 are black and lettered, non-significant movements coloured grey); ( $g$-i) show social network diagrams where nodes (circles) represent each hihi and are coloured according to the location in ( $d$-f) where they were seen most often. Lines (edges) represent associations. Strongly associating nodes cluster together more. 
Table 4. Mixing matrices showing distribution of edge weights between adults ("A")

403

404

405

406

(a)

\begin{tabular}{cccc}
\hline $\mathbf{A}$ & 0.208 & - & 0.414 \\
$\mathbf{J}$ & 0.206 & 0.381 & 0.587 \\
$\mathbf{b}_{\mathbf{i}}{ }^{\mathbf{w}}$ & 0.414 & 0.587 & 1.000
\end{tabular}

(b)

\begin{tabular}{cccc}
\hline & $\mathrm{A}$ & $\mathrm{J}$ & $\mathrm{a}_{\mathrm{i}}^{\mathrm{w}}$ \\
\hline $\mathbf{A}$ & 0.121 & - & 0.268 \\
$\mathbf{J}$ & 0.146 & 0.586 & 0.733 \\
$\mathbf{b}_{\mathbf{i}}^{\mathrm{w}}$ & 0.268 & 0.733 & 1.000
\end{tabular}

407

408

(c)

\begin{tabular}{cccc}
\hline & A & J & $a_{i}{ }^{w}$ \\
\hline $\mathbf{A}$ & 0.111 & - & 0.273 \\
$\mathbf{J}$ & 0.162 & 0.565 & 0.727 \\
$\mathbf{b}_{\mathbf{i}} \mathbf{w}$ & 0.273 & 0.727 & 1.000
\end{tabular}

409

410

411

412

Table 5. Principle components analysis (PCA) of juvenile social behaviours seen in group sites. The first three components accounted for more than $75 \%$ of variance (components $4-6$ accounted for $21.5 \%$ variance in total and are not presented). Behaviours that loaded most on each PC are highlighted in bold.

416

\begin{tabular}{lccc}
\hline & PC1 & PC2 & PC3 \\
\hline Chased & 0.13 & $\mathbf{0 . 6 2}$ & $\mathbf{- 0 . 7 4}$ \\
Followed & 0.03 & 0.00 & 0.00 \\
Chase & 0.04 & 0.09 & $\mathbf{0 . 3 7}$ \\
Follow & 0.04 & 0.01 & 0.03 \\
Huddle & 0.16 & $-\mathbf{0 . 7 8}$ & $-\mathbf{0 . 5 4}$ \\
Playfight & -0.98 & -0.03 & -0.17 \\
& & & \\
Eigenvalue & 0.11 & 0.07 & 0.06 \\
\% variance explained & 36.7 & 23.2 & 18.6 \\
\hline
\end{tabular}


Table 6. Results of a binomial GLM analysing variation in degree rank depending on PC1, PC2, and PC3 describing variation in interactions between juvenile hihi (Table 5). Coefficients, standard errors and $z$ values are presented. Both the $P$-value of the model and the $P$-value generated using coefficients from 1000 randomised networks (specified as $P_{\text {rand }}$ ) are presented, for comparison. Marginal significance of PC3 indicated with ".".

428 Quantifying movement $(\Psi)$ in our multistate analysis showed a low likelihood that hihi transitioned 429 between group sites, although this did vary depending on where birds were moving to and from (Table 430 3, Figure 2d, e, f; Supplementary Table 1). Movement also depended on age, and some juveniles did 431 move groups between each survey (Table 3; Figure 2d, e, f; Supplementary Table 1). However, on 432 average only two or three juveniles moved between each survey (mean: $2015=2 ; 2016=3 ; 2017=3$ ), 433 and movement also varied among individuals (maximum number of moves per individual: $2015=3$; $4342016=7 ; 2017=7$; juveniles that never moved groups: $2015=29 / 37 ; 2016=35 / 79 ; 2017=56 / 91$ ). 435 Furthermore, in the social network analysis we found that juvenile-only networks showed strong positive 436 assortment by primary group in all three years, while associations among juveniles resident in different 437 sites were much weaker (Table 7; Figure 2g, h, i; 2015: $r=0.513, P_{\text {rand }}<0.001 ; 2016: r=0.32, P_{\text {rand }}<$ $\left.438 \quad 0.001 ; 2017: r=0.58, P_{\text {rand }}<0.001\right)$. 
(a)

\begin{tabular}{cccc}
\hline & Site $\mathbf{a}$ & Site $\mathbf{b}$ & $\mathbf{a}_{\mathbf{i}}{ }^{\mathbf{w}}$ \\
\hline Site $\mathbf{a}$ & 0.330 & - & 0.450 \\
Site $\mathbf{b}$ & 0.121 & 0.429 & 0.550 \\
$\mathbf{b}_{\mathbf{i}}{ }^{\mathbf{w}}$ & 0.450 & 0.550 & 1.000 \\
\hline
\end{tabular}

Table 7. Mixing matrices showing distribution of edge weights between juveniles depending on the group where they were most commonly located (site lettering refers to group locations in Figure 6) in (a) 2015, (b) 2016 and (c) 2017. $\mathrm{ai}^{\mathrm{w}}$ are the row sums, $b_{i}{ }^{w}$ are the column sums; due to rounding, sum values may not be exact. Tables are symmetrical so half the values are presented.

(b)

\begin{tabular}{ccccc}
\hline & Site c & Site d & Site b & $\mathbf{a}_{\mathbf{i}} \mathbf{w}$ \\
\hline Site c & 0.503 & - & - & 0.653 \\
Site d & 0.141 & 0.144 & - & 0.298 \\
Site b & 0.009 & 0.013 & 0.027 & 0.049 \\
$\mathbf{b}_{\mathbf{i}}{ }^{\mathbf{w}}$ & 0.653 & 0.298 & 0.049 & 1.000
\end{tabular}

(c)

\begin{tabular}{ccccc}
\hline & Site d & Site $\mathbf{b}$ & Site e & $\mathbf{a}_{\mathbf{i}}{ }^{\mathbf{w}}$ \\
\hline Site d & 0.575 & - & - & 0.674 \\
Site $\mathbf{b}$ & 0.028 & 0.155 & - & 0.189 \\
Site e & 0.071 & 0.006 & 0.061 & 0.137 \\
$\mathbf{b}_{\mathbf{i}}{ }^{\mathbf{w}}$ & 0.674 & 0.189 & 0.137 & 1.000
\end{tabular}

\section{WERE JUVENILES RELATED TO ADULTS AND OTHER JUVENILES?}

In the re-sighting data each year there were very few occasions when juveniles were seen in the same group during the same survey as their parents (mean \pm S.E. proportion of surveys: $2015=0.02 \pm 0.02$; $2016=0.03 \pm 0.01 ; 2017=0.08 \pm 0.02$ ), or their maternal-siblings (Figure 3a; mean \pm S.E. proportion of surveys: $2015=0.22 \pm 0.08 ; 2016=0.25 \pm 0.04 ; 2017=0.28 \pm 0.04)$. Individuals that grouped closer to their nest-of-origin were not more likely to be seen with maternal-siblings each year (Figure 3b; null model highest ranked; Supplementary Table 2). Being recorded in more surveys also did not affect cooccurrence with maternal-siblings in any year (Supplementary Table 2). Together, this low likelihood of juveniles being resident with parents or maternal-siblings suggested that these individuals had very limited opportunities to associate, so we did not analyse assortment by relatedness in networks. 
(a)

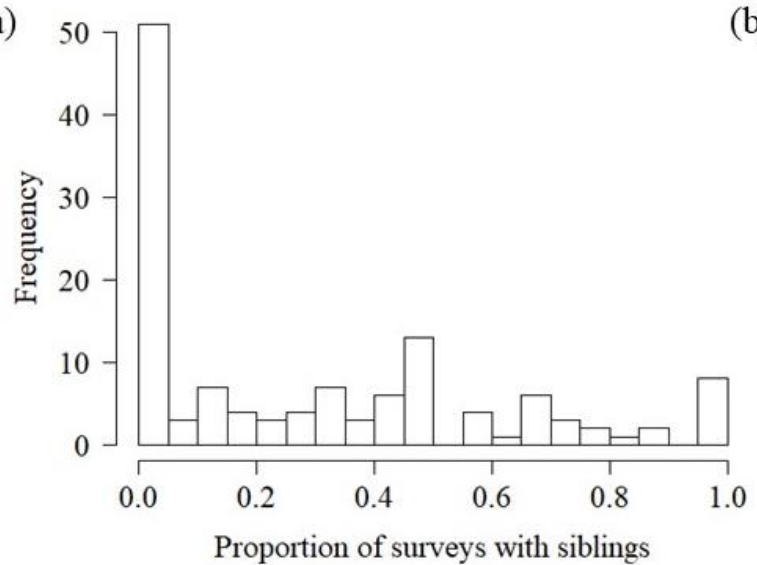

(b)

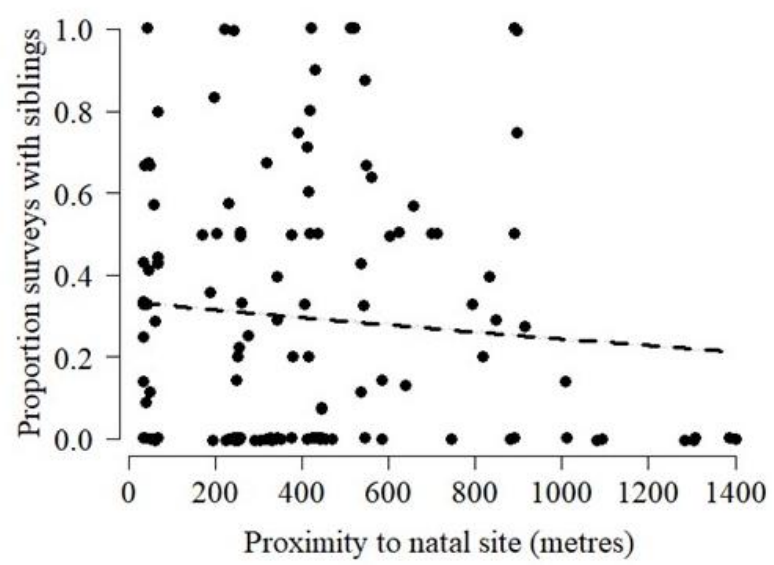

Figure 3. (a) Variation among juveniles in the proportion of occasions where they were recorded with their maternal-siblings (all years of the study included), and (b) relationship between proportion of occasions seen with siblings and the distance from each juvenile's natal site to where they grouped. In (b), confidence intervals were too narrow to plot (Supplementary Table 2).

Here we used both a multistate analysis and social network analysis approach to characterise the location use, age composition, and relatedness of hihi groups that form at the end of each breeding season. We found that groups formed non-randomly and occurred in consistent locations within each 474 year, with little movement across our study site. Multistate analysis indicated that groups were formed predominantly of juveniles, and although some adults were observed their presence was more transient.

476 Network associations reflected these differences in residency: rather than associating with adults, juveniles most strongly associated with other juveniles frequently present in the same group locations.

478 Juveniles also interacted more frequently with other birds compared to adults. However, despite differences among individuals in the amount of affiliative- or aggressive-type interactions, the types of

480 behavioural interactions did not significantly predict a juveniles' number of network associates. Finally, 481 juveniles were almost never seen with their parents (occurred in only $2-8 \%$ of surveys across the study) 482 and were also re-sighted without their nest mates in the majority (72-78\%) of surveys. Together, these results suggest juvenile hihi groups most closely resemble the "gangs" described in juvenile ravens by 
Dall and Wright (2009) (Table 3.1), where juvenile birds aggregate around communal roosts (Wright, Stone and Brown, 2003) or other social meeting places (Ward and Zahavi, 2008) which are separate from main colonies and thus have limited interaction with adults. This is in contrast to flocks, which can move over large distances (Templeton et al., 2012) or crèches, where juveniles associate with related adults (Balda and Balda, 1978).

Animals can aggregate if ecological factors (such as rich foraging grounds) cause them to coexist in the same place at the same time (Mourier, Vercelloni and Planes, 2012; Strandburg-Peshkin et al., 2017;

492 Gall and Manser, 2018), but location use can also arise as a consequence of preferring to associate with others (Fletcher, 2007; Firth and Sheldon, 2016). The aggregations of juvenile hihi we detected

494 here could have been a by-product of differential habitat use according to age to avoid competition with more dominant adults (Catterall, Kikkawa and Gray, 1989; Marchetti and Price, 1989; Sol et al., 1998).

496 Alternatively, groups could have arisen through juveniles choosing to associate with individuals of a similar phenotype (Croft et al., 2005). Understanding the intricate link between current environment and how or why associations form is still a fledgling topic in social network analysis (Madden et al., 2009; Godfrey, Sih and Bull, 2013; Pinter-Wollman et al., 2013; Leu et al., 2016). We did not explicitly test this link here (for example, by changing the environment and comparing network structures (Formica et al., 2016)) so cannot fully conclude if ecology or individual choice determined group associations. However, repeating observations across years did show similar characteristics in groups and their locations, albeit with a small level of variation, perhaps suggesting climatic conditions or other ecological variables of the sites affected group formation (Krause and Ruxton, 2002). Thus, the value of long term studies is that they allow for replicates that demonstrate whether the same determinants structure animal groups across years (Shizuka et al., 2014) especially when individual identities differ year-on-year (as in our study, with different juvenile cohorts).

509 Regardless of whether groups arose due to active choice by individuals or a more incidental aggregation 510 based on environment, the result was that non-random associations formed between juveniles which 511 could mediate behaviours such finding food, and avoiding predators or disease (Krause and Ruxton, 512 2002; Krause, Lusseau and James, 2009; Drewe, 2010; Aplin et al., 2012; Schakner et al., 2017). As 513 we found limited co-occurrence and associations between differently-aged animals, are there benefits 
514 to aggregating with other juveniles rather than adults? This could be a potentially risky strategy as young 515 animals are naïve (Galef and Laland, 2005) and do not always behave appropriately to suit the current 516 environment (Clayton, 1994). Individuals appear to recognise these risks in some species (such as capuchin monkeys, Cebus apella) and prefer to pay attention to adults rather than juveniles if given the 518 choice (Ottoni, De Resende and Izar, 2005). However, in gang-type groups the limited presence of adults creates little opportunity to associate with these more experienced individuals, in contrast to flocks (Templeton et al., 2012) or crèches (Heinsohn, 1991).

While young animals by themselves may be naïve, large groups of juveniles are still thought to be beneficial because they can act as "information centres" (Dall and Wright, 2009) where associating with many animals collectively gathering and sharing information may help overcome any one individual's inexperience (Ward and Zahavi, 2008). For example, in quelea (Quelea quelea), parents leave their young after approximately three weeks of care, and young then form assemblages which help them to exploit their habitat and forage successfully without learning from adults (Ward and Zahavi, 2008). Similarly, juvenile raven gangs respond collectively to new, ephemeral, food sources (Marzluff, Heinrich and Marzluff, 1996; Dall and Wright, 2009). Furthermore, in this context other factors such as relatedness may not be important for grouping because non-kin provide a broader range of information collected from different experiences, which could be more relevant to the current environment (Schwab, Bugnyar and Kotrschal, 2008; Kulahci et al., 2016). Young animals are known to pay more attention to non-kin particularly when early life conditions were suboptimal, suggesting they adjust associations

534 depending on payoff (Farine, Spencer and Boogert, 2015). Hihi do have high rates of extra-pair paternity 535 (Brekke et al., 2013), and unfortunately genetic data was not available at the time of the study, but the 536 general low presence of adults or half-siblings suggests relatedness was not important to their grouping 537 (Saitou, 1978, 1979; Hirsch et al., 2013; Arnberg et al., 2015). Overall, if hihi juvenile groups may be 538 information centres then it will be valuable to test how they inform foraging behaviour.

540 While aggregating, juvenile hihi interacted directly with other individuals. Some behaviours were not 541 equal (for example, a hihi that was chased did not then become the chaser) and so could be establishing dominance in these groups (Drews, 1993). Other behaviours appeared to be affiliative, and consistent 
543 with definitions of social play (Diamond and Bond, 2003). Social play is known in other gang-forming

544 juveniles (ravens) (Heinrich and Smolker, 1998; Diamond and Bond, 2003) and is generally thought to

545 be a more complex behaviour associated with large brain sizes, but previous reviews have cautioned

546 that its apparent absence in other species could be due to a lack of research (Diamond and Bond, 2003).

547 Interactions between juveniles have been suggested to be one route by which information is shared in

548 other species (Diamond and Bond, 2003). However, we did not find a link between likelihood of

549 interacting and network position (degree). This may indicate interactions and familiarity between specific

550 individuals are not crucial to information dissemination in young hihi (Schwab, Bugnyar and Kotrschal,

551 2008; Guillette, Scott and Healy, 2016; Ramakers et al., 2016), as an individual's number of associates

552 can be important for information acquisition (Aplin et al., 2012; Snijders et al., 2014). As yet, it remains

553 unclear what structures juvenile hihi network position in groups, so further work is needed to test why

554 groups form and how this influences sociality, to help further understand the importance of group

555 structure for learning in young birds.

556

557 To conclude, we show that juvenile hihi are commonly found in groups during their first few months of 558 independence from parents. These groups form in spatially-separated locations and are dominated by 559 juveniles, with little opportunity to interact with adults. The structure of gang-like groups in young hihi 560 create the potential for many naïve individuals to associate, and potentially share information, Next, it 561 will be valuable to test more explicitly whether these groups inform behaviour in young hihi. By doing 562 so, we can explore if such groups provide opportunities to help young birds overcome any one 563 individual's disadvantage of being naïve, or whether there are downsides of associating with 564 inexperienced peers.

565

\section{Acknowledgements}

568 We are grateful to the Department of Conservation and Supporters of Tiritiri Matangi for their permission to conduct this research. 


\section{References}

Aplin, L. M., Farine, D. R., Morand-Ferron, J. and Sheldon, B. C. (2012) Social networks predict patch discovery in a wild population of songbirds, Proceedings of the Royal Society B: Biological Sciences, 279(1745), pp. 4199-4205. doi: 10.1098/rspb.2012.1591.

Arnberg, N. N., Shizuka, D., Chaine, A. S. and Lyon, B. E. (2015) Social network structure in wintering golden-crowned sparrows is not correlated with kinship, Molecular Ecology, 24(19), pp. 50345044. doi: $10.1111 / \mathrm{mec} .13366$.

Balda, R. P. and Balda, J. H. (1978) The care of young Piñon Jays (Gymnorhinus cyanocephalus) and their integration into the flock, Journal für Ornithologie, 119, pp. 146-171. doi: https://doi.org/10.1007/BF01644586.

Bastian, M., Heymann, S. and Jacomy, M. (2009) Gephi: An Open Source Software for Exploring and Manipulating Networks, Third International AAAI Conference on Weblogs and Social Media, pp. 361-362.

Le Bohec, C., Gauthier-Clerc, M. and Le Maho, Y. (2005) The adaptive significance of crèches in the king penguin, Animal Behaviour, 70(3), pp. 527-538. doi: 10.1016/j.anbehav.2004.11.012.

Brekke, P., Cassey, P., Ariani, C. and Ewen, J. G. (2013) Evolution of extreme-mating behaviour: patterns of extrapair paternity in a species with forced extrapair copulation, Behavioral Ecology and Sociobiology, 67(6), pp. 963-972. doi: 10.1007/s00265-013-1522-9.

Budaev, S. V. (2010) Using principal components and factor analysis in animal behaviour research: Caveats and guidelines, Ethology, 116(5), pp. 472-480. doi: 10.1111/j.1439-0310.2010.01758.x.

Burnham, K. P. and Anderson, D. R. (2002) Model selection and multimodel inference: a practical

Cam, E., Oro, D., Pradel, R. and Jimenez, J. (2004) Assessment of hypotheses about dispersal in a long-lived seabird using multistate capture-recapture models, Journal of Animal Ecology, 73(4), pp. 723-736. doi: 10.1111/j.0021-8790.2004.00848.x.

Catterall, C. P., Kikkawa, J. and Gray, C. (1989) Inter-related age-dependent patterns of ecology and behaviour in a population of silvereyes (Aves: Zosteropidae), Journal of Animal Ecology, 58(2), 
601 Clayton, N. S. (1994) The role of age and experience in the behavioural development of food-storing and retrieval in marsh tits, Parus palustris, Animal Behaviour, 47, pp. 1435-1444. doi: 10.1006/anbe.1994.1190.

604

Clayton, N. S. and Emery, N. J. (2007) The social life of corvids, Current Biology, 17(16). doi: 10.1016/j.cub.2007.05.070.

Coussi-Korbel, S. and Fragaszy, D. M. (1995) On the relation between social dynamics and social learning, Animal Behaviour, 50, pp. 1441-1453. doi: 10.1016/0003-3472(95)80001-8.

Croft, D. P., James, R., Ward, A. W., Botham, M. S., Mawdsley, D. and Krause, J. (2005) Assortative interactions and social networks in fish, Oecologia, 143(2), pp. 211-219. doi: 10.1007/s00442-

611 Croft, D. P., Madden, J. R., Franks, D. W. and James, R. (2011) Hypothesis testing in animal social networks, Trends in Ecology \& Evolution, 26(10), pp. 502-507.

613 Dall, S. R. X., Giraldeau, L.-A., Olsson, O., McNamara, J. M. and Stephens, D. W. (2005) Information and its use by animals in evolutionary ecology, Trends in Ecology \& Evolution, 20(4), pp. 187193. doi: 10.1016/j.tree.2005.01.010.

Dall, S. R. X. and Wright, J. (2009) Rich pickings near large communal roosts favor 'gang' foraging by juvenile common ravens, Corvus corax, PLoS ONE. Edited by F. R. Adler, 4(2), p. e4530. doi: 10.1371/journal.pone.0004530.

Diamond, J. and Bond, A. B. (2003) A comparative analysis of social play in birds, Behaviour, 140(89), pp. 1091-1115. doi: 10.1163/156853903322589650.

Drewe, J. A. (2010) Who infects whom? Social networks and tuberculosis transmission in wild meerkats, Proceedings of the Royal Society B: Biological Sciences, 277(1681), pp. 633-42. doi: 10.1098/rspb.2009.1775.

Drews, C. (1993) The concept and definition of dominance in animal behaviour, Behaviour, 125(3-4), pp. 283-313. doi: 10.1163/156853993X00290.

Ekman, J. (1989) Ecology of non-breeding social systems of Parus, The Wilson Bulletin, 101(2), pp. 263-288. doi: 10.2307/4162729.

Ewen, J. G. and Armstrong, D. P. (2000) Male provisioning is negatively correlated with attempted 
631 Ewen, J. G., Armstrong, D. P. and Lambert, D. M. (1999) Floater males gain reproductive success through extrapair fertilizations in the stitchbird, Animal Behaviour, 58(2), pp. 321-328. doi: 10.1006/anbe.1999.1150.

634 Farine, D. R. (2013) Animal social network inference and permutations for ecologists in R using asnipe, Methods in Ecology and Evolution, 4(12), pp. 1187-1194. doi: 10.1111/2041210X.12121.

637 Farine, D. R. (2014) Measuring phenotypic assortment in animal social networks: Weighted associations are more robust than binary edges, Animal Behaviour, pp. 141-153. doi: 10.1016/j.anbehav.2014.01.001.

640 Farine, D. R. (2017) A guide to null models for animal social network analysis, Methods in Ecology and Evolution, 8(10), pp. 1309-1320. doi: 10.1111/2041-210X.12772.

642 Farine, D. R., Spencer, K. A. and Boogert, N. J. (2015) Early-life stress triggers juvenile zebra finches to switch social learning strategies, Current Biology, 25(16), pp. 2184-2188. doi: 10.1016/j.cub.2015.06.071.

Farine, D. R. and Whitehead, H. (2015) Constructing, conducting and interpreting animal social network analysis, Journal of Animal Ecology, 84(5), pp. 1144-1163. doi: 10.1111/13652656.12418.

Firth, J. A. and Sheldon, B. C. (2016) Social carry-over effects underpin trans-seasonally linked structure in a wild bird population, Ecology Letters, pp. 1324-1332. doi: 10.1111/ele.12669.

Fletcher, R. J. (2007) Species interactions and population density mediate the use of social cues for habitat selection., Journal of Animal Ecology, 76(3), pp. 598-606. doi: 10.1111/j.1365-

Formica, V., Wood, C., Cook, P. and Brodie, E. (2016) Consistency of animal social networks after disturbance, Behavioral Ecology, 00(00), pp. 1-9. doi: 10.1093/beheco/arw128.

Franks, V. R. and Thorogood, R. (2018) Older and wiser? Age differences in foraging and learning by an endangered passerine, Behavioural Processes, 148, pp. 1-9. doi: 10.1016/j.beproc.2017.12.009.

Galef, B. G. and Laland, K. N. (2005) Social Learning in Animals: Empirical Studies and Theoretical Models, BioScience, 55(6), p. 489. doi: 10.1641/0006-3568(2005)055[0489:SLIAES]2.0.CO;2. 
social and ecological factors, Behavioral Ecology and Sociobiology, 72(5), p. 77. doi: $10.1007 / \mathrm{s} 00265-018-2490-x$.

Gath, H. (2017) Conservation management of the endangered Mauritius parakeet Psittacula echo (PhD thesis). University College London, U.K.

Godfrey, S. S., Bull, C. M., James, R. and Murray. (2009) Network structure and parasite transmission in a group living lizard, the gidgee skink, Egernia stokesii, Behavioral Ecology and Sociobiology, 63(7), pp. 1045-1056. doi: 10.1007/s00265-009-0730-9.

Godfrey, S. S., Sih, A. and Bull, C. M. (2013) The response of a sleepy lizard social network to altered ecological conditions, Animal Behaviour, 86(4), pp. 763-772. doi:

Gompper, M. E. (1996) Sociality and asociality in white-nosed coatis (Nasua narica): Foraging costs and benefits, Behavioral Ecology, 7(3), pp. 254-263. doi: 10.1093/beheco/7.3.254.

Guillette, L. M., Scott, A. C. . and Healy, S. D. (2016) Social learning in nest-building birds: a role for familiarity, Proceedings of the Royal Society B: Biological Sciences, 283(1827), p. 20152685. doi: $10.1098 / \mathrm{rspb} .2015 .2685$.

Hass, C. C. and Valenzuela, D. (2002) Anti-predator benefits of group living in white-nosed coatis (Nasua narica), Behavioral Ecology and Sociobiology, 51(6), pp. 570-578. doi: 10.1007/s00265002-0463-5.

Hatch, K. K. and Lefebvre, L. (1997) Does father know best? Social learning from kin and non-kin in juvenile ringdoves, Behavioural Processes, 41(1), pp. 1-10. doi: 10.1016/S0376-6357(97)00022-

Heinrich, B. and Smolker, R. (1998) Play in common ravens (Corvus corax), in Bekoff, M. and Byers, J. A. (eds) Animal Play. Cambridge: Cambridge University Press, pp. 27-44. doi: 10.1017/CBO9780511608575.003. breeding white-winged choughs, The American Naturalist, 137(6), pp. 864-881. doi: $10.1086 / 285198$. 
691 Jolly, G. M. (1982) Mark-recapture models with parameters constant in time., Biometrics, 38(2), pp. 301-21. doi: $10.2307 / 2530445$.

693 Krause, J., James, R., Franks, D. W. and Croft, D. P. (eds) (2015) Animal Social Networks. Oxford: $694 \quad$ Oxford University Press.

695 Krause, J., Lusseau, D. and James, R. (2009) Animal social networks: an introduction, Behavioral 696 Ecology and Sociobiology, 63(7), pp. 967-973. doi: 10.1007/s00265-009-0747-0.

697 Krause, J. and Ruxton, G. D. (2002) Living in Groups. Oxford: Oxford University Press. doi: $10.1093 /$ sysbio/sys022.

699 Kulahci, I. G., Rubenstein, D. I., Hoppitt, W., Mikus, N. and Schwab, C. (2016) Social networks predict selective observation and information spread in ravens, Royal Society Open Science, 3, p. 160256. doi: $10.1098 /$ rsos. 160256 .

Leu, S. T., Farine, D. R., Wey, T. W., Sih, A. and Bull, C. M. (2016) Environment modulates population social structure: Experimental evidence from replicated social networks of wild lizards, Animal Behaviour, 111, pp. 23-31. doi: 10.1016/j.anbehav.2015.10.001.

Lind, A. J. and Welsh, H. H. (1994) Ontogenetic changes in foraging behaviour and habitat use by the Oregon garter snake, Thamnophis atratus hydrophilus, Animal Behaviour, 48, pp. 1261-1273. doi: DOI: 10.1006/anbe.1994.1362.

Low, M. and Pärt, T. (2009) Patterns of mortality for each life-history stage in a population of the

Madden, J. R., Drewe, J. A., Pearce, G. P. and Clutton-Brock, T. H. (2009) The social network structure of a wild meerkat population: 2. Intragroup interactions, Behavioral Ecology and Sociobiology, 64(1), pp. 81-95. doi: 10.1007/s00265-009-0820-8.

Marchetti, K. and Price, T. (1989) Differences in the foraging of juvenile and adult birds: the importance of developmental constraints, Biological Reviews, 64(1), pp. 51-70. doi: 10.1111/j.1469-185X.1989.tb00638.x.

Martin, J., Nichols, J. D., Kitchens, W. M. and Hines, J. E. (2006) Multiscale patterns of movement in fragmented landscapes and consequences on demography of the snail kite in Florida, Journal of Animal Ecology, 75(2), pp. 527-539. doi: 10.1111/j.1365-2656.2006.01073.x. 
Cooperative Corvid. London: A\&C Black.

Marzluff, J. M., Heinrich, B. and Marzluff, C. S. (1996) Raven roosts are mobile information centres, Animal Behaviour, 51(1), pp. 89-103. doi: 10.1006/anbe.2000.1579.

Mazerolle, M. J. (2017) AICcmodavg: model selection and multimodel inference based on (Q)AIC(c).

McCready, M. and Ewen, J. G. (2016) Hihi (Stitchbird) Breeding on Tiritiri Matangi Island: 2015-2016 Breeding Season. Internal report. New Zealand.

McCready, M. and Ewen, J. G. (2017) Hihi (Stitchbird) Breeding on Tiritiri Matangi Island: 2016-2017 Breeding Season. Internal report. New Zealand.

Molvar, E. M. and Bowyer, R. T. (1994) Costs and benefits of group living in a recently social ungulate: the Alaskan moose, Journal of Mammalogy, 75(3), pp. 621-630. doi: 10.2307/1382509.

Morse, D. H. (1978) Structure and foraging patterns of flocks of tits and associated species in an English woodland during the winter, Ibis, 120(3), pp. 298-312. doi: 10.1111/j.1474919X.1978.tb06790.x.

Mourier, J., Vercelloni, J. and Planes, S. (2012) Evidence of social communities in a spatially structured network of a free-ranging shark species, Animal Behaviour, 83(2), pp. 389-401. doi: 10.1016/j.anbehav.2011.11.008.

Naef-Daenzer, B., Widmer, F. and Nuber, M. (2001) Differential post-fledging survival of great and coal tits in relation to their condition and fledging date, Journal of Animal Ecology, 70(5), pp. 730-738. doi: 10.1046/j.0021-8790.2001.00533.x.

Newman, M. (2002) Assortative Mixing in Networks, Physical Review Letters, 89(20), p. 208701. doi: 10.1103/PhysRevLett.89.208701.

Ottoni, E. B., De Resende, B. D. and Izar, P. (2005) Watching the best nutcrackers: What capuchin monkeys (Cebus apella) know about others' tool-using skills, Animal Cognition, 8(4), pp. 215219. doi: $10.1007 / \mathrm{s} 10071-004-0245-8$.

Pinter-Wollman, N., Hobson, E., Smith, J. E., Edelman, A. J., Shizuka, D., de Silva, S., Waters, J. S., Prager, S. D., Sasaki, T., Wittemyer, G., Fewell, J. and McDonald, D. B. (2013) The dynamics of animal social networks: analytical, conceptual, and theoretical advances, Behavioral Ecology, 25(2), pp. 242-255. doi: 10.1093/beheco/art047. 
reduce group success, Proceedings of the Royal Society B: Biological Sciences, 283(1823), p. 20152888. doi: 10.1098/rspb.2015.2888.

Psorakis, I., Voelkl, B., Garroway, C. J., Radersma, R., Aplin, L. M., Crates, R. A., Culina, A., Farine, D. R., Firth, J. A., Hinde, C. A., Kidd, L. R., Milligan, N. D., Roberts, S. J., Verhelst, B. and Sheldon, B. C. (2015) Inferring social structure from temporal data, Behavioral Ecology and Sociobiology, 69(5), pp. 857-866. doi: 10.1007/s00265-015-1906-0.

R Core Team (2017) R Software, R: A Language and Environment for Statistical Computing. Vienna, Austria: R Foundation for Statistical Computing.

Ramakers, J. J. C., Dechmann, D. K. N., Page, R. A. and O’Mara, M. T. (2016) Frugivorous bats prefer information from novel social partners, Animal Behaviour, 116, pp. 83-87. doi: 10.1016/j.anbehav.2016.03.021.

Rubenstein, D. I. (1978) On Predation, Competition, and the Advantages of Group Living, in Bateson, P. P. G. and Klopfer, P. H. (eds) Social Behavior. Boston: Springer, pp. 205-231.

Saitou, T. (1978) Ecological study of social organization in the great tit, Parus major 1. Basic structure of the winter flocks, Japanese Journal of Ecology, 28, pp. 199-214.

Saitou, T. (1979) Ecological study of social organization in the great tit, Parus major 3. Home range of the basic flocks and dominance relationship of the members in a basic flock, Journal of the Yamashina Institute for Ornithology, 11, pp. 149-171.

van Schaik, C. P. (2010) Social learning and culture in animals, in Kappeler, P. (ed.) Animal Behaviour: Evolution and Mechanisms. Berlin, Heidelberg: Springer, pp. 623-653. doi: 10.1007/978-3-642-02624-9_20.

Schakner, Z. A., Petelle, M. B., Tennis, M. J., Van der Leeuw, B. K., Stansell, R. T. and Blumstein, D. T. (2017) Social associations between California sea lions influence the use of a novel foraging ground, Royal Society Open Science, 4(5), p. 160820. doi: 10.1098/rsos.160820.

Schwab, C., Bugnyar, T. and Kotrschal, K. (2008) Preferential learning from non-affiliated individuals in jackdaws (Corvus monedula), Behavioural Processes, 79(3), pp. 148-155. doi: 10.1016/j.beproc.2008.07.002. 10.1016/j.anbehav.2007.06.006. 
Seppänen, J. T., Forsman, J. T., Monkkönen, M. and Thomson, R. L. (2007) Social information use is a process across time, space, and ecology, reaching heterospecifics, Ecology, 88(7), pp. 16221633. doi: $10.1890 / 06-1757.1$.

Shizuka, D., Chaine, A. S., Anderson, J., Johnson, O., Laursen, I. M. and Lyon, B. E. (2014) Acrossyear social stability shapes network structure in wintering migrant sparrows, Ecology Letters, 17(8), pp. 998-1007. doi: 10.1111/ele.12304.

Sih, A., Hanser, S. F. and McHugh, K. A. (2009) Social network theory: new insights and issues for behavioral ecologists, Behavioral Ecology and Sociobiology, 63(7), pp. 975-988. doi: 10.1007/s00265-009-0725-6.

Smith, D. and Ewen, J. G. (2015) Hihi (Stitchbird) Breeding on Tiritiri Matangi Island: 2014-2015 Breeding Season. Internal report. New Zealand.

Snijders, L., van Rooij, E. P., Burt, J. M., Hinde, C. A., van Oers, K. and Naguib, M. (2014) Social networking in territorial great tits: Slow explorers have the least central social network positions, Animal Behaviour, 98, pp. 95-102. doi: 10.1016/j.anbehav.2014.09.029.

Sol, D., Santos, D. ., Garcia, J. and Cuadrado, M. (1998) Competition for food in urban pigeons: the cost of being juvenile, Condor, 100(2), pp. 298-304. doi: 10.2307/1370270.

Strandburg-Peshkin, A., Farine, D. R., Crofoot, M. C. and Couzin, I. D. (2017) Habitat and social factors shape individual decisions and emergent group structure during baboon collective movement, eLife, 6. doi: 10.7554/eLife.19505.

Sullivan, K. A. (1989) Predation and Starvation: Age-Specific Mortality in Juvenile Juncos (Junco phaenotus), The Journal of Animal Ecology, 58(1), p. 275. doi: 10.2307/5000.

Templeton, C. N., Reed, V. A., Campbell, S. E. and Beecher, M. D. (2012) Spatial movements and social networks in juvenile male song sparrows, Behavioral Ecology, 23(1), pp. 141-152. doi: 10.1093/beheco/arr167.

Thornton, A. (2006) Teaching in Wild Meerkats, Science, 313(5784), pp. 227-229. doi:

810 Thornton, A. and Raihani, N. J. (2010) Identifying teaching in wild animals, Learning \& Behavior, 
38(3), pp. 297-309. doi: 10.3758/LB.38.3.297.

812 Velando, A. (2001) Postfledging crèche behavior in the European shag, Journal of Ethology, 19, pp. $121-127$.

van de Waal, E., Bshary, R. and Whiten, A. (2014) Wild vervet monkey infants acquire the foodprocessing variants of their mothers, Animal Behaviour, 90, pp. 41-45. doi: 10.1016/j.anbehav.2014.01.015.

Ward, A. and Webster, M. (2016) Sociality: the Behaviour of Group-Living Animals. doi: 10.1007/9783-319-28585-6.

Ward, P. and Zahavi, A. (2008) The importance of certain assemblages of birds as 'information centres' for food finding, Ibis, 115(4), pp. 517-534. doi: 10.1111/j.1474-919X.1973.tb01990.x.

Wey, T., Blumstein, D. T., Shen, W. and Jordán, F. (2008) Social network analysis of animal behaviour: a promising tool for the study of sociality, Animal Behaviour, 75(2), pp. 333-344. doi: 10.1016/j.anbehav.2007.06.020.

White, G. C. and Burnham, K. P. (1999) Program MARK: Survival estimation from populations of marked animals, Bird Study, 46, pp. S120-S139. doi: 10.1080/00063659909477239.

826 White, G. C., Kendall, W. L. and Barker, R. J. (2006) Multistate Survival Models and Their Extensions in Program MARK, The Journal of Wildlife Management, 70(6), pp. 1521-1529.

828 Wright, J., Stone, R. E. and Brown, N. (2003) Communal roosts as structured information centres in 